\title{
DISLEXIA NO CONTEXTO EDUCACIONAL
}

\author{
DYSLEXIA IN THE EDUCATIONAL CONTEXT
}

\author{
Rosimeire Batista Sampaio Taborda \\ Fabio José Antônio da Silva ${ }^{2}$
}

RESUMO: Os transtornos da aprendizagem têm ganhado cada vez mais destaque no ambiente escolar e um grande número de alunos são diagnosticados com dificuldades de aprendizagem, refletindo diretamente do desempenho acadêmico. A dislexia é caracterizada como um transtorno da aprendizagem que abrange dificuldades na leitura, escrita e soletração, podendo ser uma ou mais combinações. $O$ indivíduo apresenta dificuldades em decodificar o estímulo escrito ou o símbolo gráfico. E uma das principais características desse transtorno é comprometimento da capacidade de aprender a ler e escrever com conformidade e fluência, implicando também na questão interpretativa e compreensiva de textos. Trata-se de um dos transtornos mais frequentes no contexto escolar. Quanto mais cedo for identificado e realizado o encaminhamento, maior será o desenvolvimento do indivíduo. O educador deve estar atento as dificuldades dos alunos, desde o início da alfabetização, conduzindo a estratégias que possibilitem uma aprendizagem mais concreta e significativa, permitindo que o aluno com dislexia se aproprie da escrita e leitura através de metodologia diferenciada que facilite aprendizagem. $\mathrm{O}$ artigo discorreu sobre a Dislexia no contexto educacional, e destacando a importância da atuação do professor durante a prática de ensino, e tornando-se relevante aos professores que trabalham com crianças que apresentam o transtorno, para que possam dar encaminhamentos metodológicos adequados, a fim de contribuir e facilitar a aprendizagem do aluno. O artigo foi norteado através de uma revisão bibliográfica acerca do tema "Dislexia no contexto educacional", descrevendo pontos relevantes à temática, através de livros e literatura disponíveis, abordando conceitos, classificações e características.

Palavras-Chave: Aprendizagem. Dislexia. Estratégias. Aluno. Professor.

ABSTRACT: Learning disorders have gained increasing prominence in the school environment and a large number of students are diagnosed with learning disabilities, directly reflecting academic performance. Dyslexia is characterized as a learning disorder that encompasses difficulties in reading, writing and spelling, and may be one or more

1 Graduação em Pedagogia Flated - Faculdade Latino-Americana de Educação. Pós-graduação em Psicopedagogia - FATEC. Pós-graduação em Psicomotricista - FATEC. Pós-graduação em TGD - FATEC. Professora da Escola Adventista de Apucarana/PR.

${ }^{2}$ Profissional de Educação Física. Mestre em Educação. Doutorando em Educação Física. 
combinations. The individual has difficulties in decoding the written stimulus or the graphic symbol. And one of the main characteristics of this disorder is impairment of the ability to learn to read and write with conformity and fluency, implying also in the interpretative and comprehensible question of texts. It is one of the most frequent disorders in the school context. The earlier the referral is identified and performed, the greater the development of the individual. The educator must be attentive to the difficulties of the students, from the beginning of literacy, leading to strategies that allow a more concrete and meaningful learning, allowing the student with dyslexia to appropriate writing and reading through a differentiated methodology that facilitates learning. The article discusses Dyslexia in the educational context, highlighting the importance of the teacher's performance during teaching practice, and becoming relevant to teachers working with children who present the disorder, so that they can provide appropriate methodological referrals in order to contribute to and facilitate student learning. The article was guided by a bibliographical review about the theme "Dyslexia in the educational context", describing relevant points to the theme, through available books and literature, addressing concepts, classifications and characteristics.

Keywords: Learning. Dyslexia. Strategies. Student. Teacher.

\section{INTRODUÇÃO}

A educação inclusiva, atualmente, tem sido vista de forma diferenciada e desafiadora em diversos âmbitos da sociedade. E dentro do contexto educacional, traz uma série de desafios que precisam ser planejados, repensados para que a educação inclusiva ocorra e atinja, de forma eficaz, os sujeitos envolvidos.

É oportuno ressaltar que, a educação inclusiva, a um passado não tão distante, era uma incógnita. Não se sabia como introduzir ou trabalhar com alunos com necessidades educacionais. Muitas ações foram desenvolvidas para tentar mitigar as dificuldades, mas não abrangiam a individualidade e a real necessidade do aluno.

Essa história vem sendo reconstruída aos poucos, e a cada dia, pesquisas mais assertivas e direcionadas, propiciam uma bagagem de informações aos agentes educacionais. Mas, sabe-se que ainda há muito caminho a percorrer, diante das constantes alterações que ocorrem nos contextos: políticos, educacionais e sociais, e também pela existência de vários tipos de necessidades educacionais especiais.

Dentro do ambiente escolar, pode-se pontuar e diferenciar as necessidades especiais como: física, visual, auditiva, altas habilidades, síndromes e transtornos do desenvolvimento. E, portanto, o meio escolar, deve abranger condições pedagógicas, físicas e políticas que venham suprir as reais necessidades dos educandos. 
Neste artigo, será enfatizado a Dislexia no contexto educacional, se objetivando em conhecer e explanar a temática, e destacar a importância da atuação do professor durante o processo de ensino-aprendizagem. Por isso, é oportuno buscar metodologias de ensino que facilitem o aprendizado do aluno com Dislexia. E tais procedimentos, sobretudo, devem respeitar as particularidades e limitações de cada sujeito, buscar formas eficazes de estimular a aprendizagem e o desenvolvimento potencial dessas crianças.

Dessa forma, o artigo se torna relevante aos professores que trabalham com crianças que apresentam o transtorno. Para que possam dar encaminhamentos metodológicos adequados, a fim de contribuir e facilitar a aprendizagem do aluno.

O artigo será norteado através de uma revisão bibliográfica acerca do tema proposto “Dislexia no contexto educacional”, descrevendo alguns pontos que norteiam à temática, através de livros e literatura disponíveis, abordando conceitos, classificações e características, processo de ensino-aprendizagem e inclusão.

\section{DESENVOLVIMENTO}

\section{I.I Transtornos de aprendizagem}

Os transtornos da aprendizagem têm ganhado cada vez mais destaque no ambiente escolar. De acordo com Morais (2006) existe um "grande número de crianças que têm recorrido a tratamentos psicopedagógicos, com dificuldades de aprendizagem”. O que consiste muitas vezes, em índices de reprovação e evasão escolar, que estão associados a crianças que apresentam dificuldades para aprender a ler a escrever (MORAIS, 2006).

Por essa razão, o autor afirma que é preciso buscar as causas de tais dificuldades para que se possa reverter ou mitigar a situação. E de acordo com pesquisas realizadas, pontuase algumas das principais causas responsáveis por tais dificuldades. Dentre elas "a falta de estimulação adequada nos pré-requisitos necessários á alfabetização; métodos de ensino inadequados; problemas emocionais; falta de maturidade para iniciar o processo de alfabetização e a dislexia" (MORAIS, 2006).

Ainda ressalta que:

Deve ficar claro que a aprendizagem da leitura e escrita é um processo complexo que envolve vários sistemas e habilidades (linguísticas, perceptuais, motoras, cognitivas), e não se pode esperar, portanto, que um determinado fator seja o único responsável pela dificuldade para aprender. $\mathrm{Na}$ verdade, os distúrbios de aprendizagem dependem de causas múltiplas, cabendo ao profissional, que realiza o diagnóstico, evidenciar a área mais comprometida e, consequentemente, recomendar a abordagem terapêutica mais indicada para a superação das dificuldades (MORAIS, 2006, p?). 
O autor também menciona outras causas, e ressalta que é essencial diagnosticar de forma precoce a causa da dificuldade em aprender, a fim de proporcionar suporte que supere as dificuldades, tanto para os educadores como para a família do educando. Uma vez que esse suporte permitirá uma melhor compreensão sobre o trato da criança e estratégias que o auxilie no processo de desenvolvimento escolar.

\section{I.I Dislexia}

A dislexia é caracterizada como um transtorno da aprendizagem que abrange dificuldades na leitura, escrita e soletração, podendo ser uma ou mais combinações dessas dificuldades. Trata-se de um transtorno genético e hereditário da linguagem, com origem neurobiológica, na qual o indivíduo apresenta dificuldade em decodificar o estímulo escrito ou o símbolo gráfico (TAVARES, 2008).

Uma das principais características desse transtorno é comprometimento da capacidade de aprender a ler e escrever com conformidade e fluência, implicando também na questão interpretativa e compreensiva de textos.

Além desses educandos diagnosticados com dislexia, possuem sua memória fonêmica

comprometida, uma vez que apresentam dificuldades em fazer a associação entre fonema e grafema (TAVARES, 2008). Tais características resultam em um déficit na parte fonológica da linguagem, dificultando outras habilidades cognitivas.

Dentre os transtornos de aprendizagem, a dislexia é um dos mais frequentes, identificados no contexto escolar. E como já mencionado, está relacionado, diretamente, à reprovação escolar, sendo ela responsável por $15 \%$ das reprovações (ABC DA SAÚDE, 2018).

O transtorno referido possui sua causa decorrente a alterações de fatores genéticos, em indivíduos que tenham familiares com problemas fonológicos, mesmo não sendo diagnosticados com dislexia. Sabe-se que o cromossomo 6 está associado ao transtorno, quando o indivíduo tenha o genitor disléxico, pode representar um risco de ser um portador do transtorno. Outro fator importante a ser considerado, é que a dislexia pode ser associada com a produção excessiva de testosterona pela mãe durante a gestação da criança (ABC DA SAÚDE, 2018; TAVARES, 2008).

A dislexia pode apresentar-se de formas diferenciadas e se manifesta de acordo com a gravidade do distúrbio. Dentre os mais comuns encontram-se dificuldades na leitura, 
escrita e soletração de palavras, dificuldades de compreender e interpretar textos verbais, identificar fonemas, dificuldades em associar letras, reconhecer rimas e símbolos e outros.

Devido a estas dificuldades, o aluno com dislexia pode apresentar uma escassez de conhecimento prévio e de vocabulário. $O$ indivíduo também tem dificuldade de organização temporal, espacial e coordenação motora.

É oportuno ressaltar que tais dificuldades, dependem da gravidade do distúrbio, e se diferenciam em cada faixa etária e escolar. No período da pré-escola, alfabetização e anos iniciais do fundamental os alunos podem apresentar problemas em seguir rotinas; aquisição tardia da fala; pronunciar sílabas de forma errada; diferenciar e sequenciar sons processo lento do vocabulário; dificuldade em reconhecer cores, números, nome, letras e símbolos; comprometimento na coordenação motora fina; dificuldades em seguir uma sequência lógico-temporal; dificuldades na execução e motora de letras, símbolos e números; orientação espacial comprometida em relação às letras e pequenas diferenças gráficas e orientação espacial confusa. No segundo ciclo do fundamental, ocorre alguns avanços, mas que ainda refletem de forma significativa na leitura e escrita (MOUSINHO et $\mathrm{al}, 2015)$.

A dislexia é um transtorno que, quanto mais cedo for identificado e realizado o devido encaminhamento, maior será o desenvolvimento do indivíduo. O educador deve estar atento as dificuldades que seus alunos apresentam desde o início da alfabetização, conduzindo a estratégias de ensino que possibilitem uma aprendizagem mais concreta e significativa, interagindo e permitindo que o aluno com dislexia se aproprie da escrita e leitura através de metodologia diferenciada que venha mitigar as dificuldades de escrita e leitura (TAVARES, 2008).

\section{I.I A importância do diagnóstico para a prática docente}

Como já mencionado, a dislexia é um transtorno que interfere na capacidade de leitura e escrita. E, cabe ao educador estar atento com as possibilidades e condições de aprendizagem, para que o indivíduo seja encaminhado para uma avaliação adequada (TAVARES, 2008).

É oportuno ressaltar que o diagnóstico é uma ferramenta que norteará todo o trabalho pedagógico, auxiliando o professor em sua prática de ensino e oportunizando uma aprendizagem concreta ao educando. Mousinho et al (2015, p?) ressaltam que: 
O diagnóstico diferencial é importante para trazer direcionamentos sobre os caminhos a seguir diante de uma determinada dificuldade. Não se trata, portanto, de um artifício médico que pretende rotular ou, simplesmente, atribuir um código numérico a uma patologia ou transtorno. Diagnosticar é, etimologicamente, "ver através de" e, neste sentido, deve fazer parte do ofício de quem ensina "ver" as condições de aprendizagem de quem aprende.

Ao perceber uma dificuldade na leitura e escrita, é preciso buscar por ajuda especializada. Vale lembrar que os problemas e/ou dificuldades de aprendizagem na leitura e escrita que indicam dislexias, apenas sugerem distúrbios de aprendizagem, não podendo atribuir um diagnóstico preciso.

Para ter a certeza de um diagnóstico de qualquer tipo de transtorno, é fundamental que o indivíduo seja submetido a uma análise multidisciplinar, o qual é realizado por uma equipe de vários profissionais treinados, dentre eles: médicos, psicólogos, psicopedagogos, fonoaudiólogos e neurologistas. Estes, por sua vez, utilizam vários testes e observações, que analisará o conjunto das manifestações de dificuldades.

É válido mencionar que para ter um diagnóstico preciso, é preciso considerar e descartar a ocorrência de deficiências visuais e auditivas, déficit de atenção, escolarização inadequada, problemas emocionais, psicológicos e socioeconômicos. Estes são fatores que podem refletir e interferir no processo de aprendizagem. Por isso a necessidade de um diagnóstico precoce para impedir que sejam atribuídos aos alunos com dislexia, rótulos que terão reflexos negativos sobre sua auto-estima e projeto de vida.

Essa avaliação multidisciplinar é muito importante para a identificação das causas das dificuldades apresentadas pelo indivíduo. E também atua como uma ferramenta que permite orientar o encaminhamento adequado para o caso individualizado.

Uma vez diagnosticada a dislexia, segundo as peculiaridades de cada caso, propiciará um encaminhamento orientado, o qual permite uma abordagem mais eficaz e proveitosa para o educador, e facilitará a aprendizagem do aluno.

\section{I.I Estratégias metodológicas para alunos com dislexia.}

Dentro do contexto educacional, há diferentes ferramentas que visam auxiliar os educadores em sua prática diária. Cabe ressaltar que, cada aluno tem necessidades diferentes, e por esse motivo, as estratégias de ensino devem abranger e considerar as necessidades e especificidades de cada educando.

Partindo desse ponto, o processo de leitura e escrita são essenciais na aquisição de novos saberes e trocas de experiências. A habilidade da escrita e leitura propiciam 
condições importantes para que o aluno esteja inserido de forma ativa no contexto educacional e social (MOUSINHO et al, 2015).

Portanto, o uso de métodos que facilitem o desenvolvimento de tais habilidades devem ser incorporados e planejados pelo educador. Mousinho et al (2015), ressaltam que “aprender a ler e escrever não é tarefa fácil para todas as pessoas, e essas podem se beneficiar com a introdução de recursos e estratégias que facilitem esse aprendizado”.

De acordo com DSM - IV (2009), a dislexia se caracteriza pela dificuldade no processo de leitura e escrita, dentro do tempo cronológico e escolar. Mousinho et al, (2015), relatam que, segundo pesquisadores de línguas regulares, indivíduos diagnosticados com dislexia, tem dificuldades na questão fonológica.

Assim, mesmo sabendo das dificuldades que abrangem o transtorno referido, os indivíduos que apresentam o transtorno, precisam "receber instrução adequada, e necessitarão de acomodações ao logo da vida" (MOUSINHO et al, 2015). E, portanto, cabe ao educador, de forma amparada por um diagnostico preciso e eficaz, propor estratégias facilitadoras para leitura e escrita.

Dentre tais estratégias, ressalta-se o papel da escola e do educador como de suma importância. Os quais devem estar de acordo a permitindo um tempo maior para a realização das atividades propostas, auxílio em atividades que sejam de caráter avaliativo para aquisição de notas em cada disciplina, as avaliações podem ser gravadas, permitir que os aluno com dislexia utilize meios alternativos para desenvolver a avaliação, ou mesmo avaliações diferenciadas.

Mousinho et al (2015) mencionam que Os alunos podem se beneficiar do uso de audiolivros, programas de computador com síntese de voz em Português, predição de palavras, programas que transformam fala em textos e organizadores de ideias.

Outro ponto que é muito importante destacar, que tais estratégias, incluem adaptações de materiais, instrucionais e relacionadas ao próprio desempenho do educando. O que irá possibilitar uma série de recursos que facilitarão o processo de aprendizagem (COMUNIDADE APRENDER CRIANÇA, 2014).

No aspecto de adaptações em materiais, o ambiente escolar, deve promover um espaço onde os textos e instruções sejam objetivos, simples e as informações mais relevantes estejam destacadas visando facilitar a compreensão do aluno. Auxiliar os educandos a definirem metas reais; oportunizar trabalhos que sejam executados de forma 
simples e por etapas, evitando desmotivar devido à quantidade e complexidade de trabalhos.

Também enfatiza a necessidade de utilizar marcadores que destaquem o texto e facilitem a leitura; trabalhar uma atividade de cada vez; e aumentar o tamanho de letras e fontes e espaçamento para o desenvolvimento das atividades. Além desses Frank (2003) complementa:

\begin{abstract}
Para atividades de leitura de livro, pode ser necessário o destaque dos pontos mais importantes: utilizar um marcador para localizar a página em que a tarefa será realizada; complementar as atividades teóricas com experiências, atividades práticas, jogos e programas de computador; fornecer um glossário sobre os termos utilizados naquela unidade; desenvolver roteiros de leitura para auxiliar a compreensão do texto; utilizar gravadores para gravar aulas, histórias, tarefas; e usar recursos de tecnologia assistiva (FRANK, 2003, p?).
\end{abstract}

Já, em relação às adaptações na forma de instrução, Mousinho et al (2015) falam que nem sempre é uma tarefa fácil manter a atenção e concentração de um aluno com dislexia. Por isso é importante propor atividades simples, dividir o ensino em partes objetivas e direcionadas às especificidades do aluno e monitorar o desenvolvimento das atividades.

Também é preciso estar sempre repetindo e relembrando conceitos e instruções, desenvolver uma rotina em sala de aula, e propor estratégias que unam a parte teórica com a prática, bem como utilizar recursos visuais para facilitar a compreensão e fixação das informações. O uso de palavras-chave também é uma estratégia eficaz que deve anteceder as novas informações. A dinâmica do trabalho em sala, interagindo os alunos, também atua como um recurso significativo no momento da aprendizagem

Deve haver equilíbrio entre o trabalho em grupos grandes, pequenos e atividades individuais. Utilizar estratégias de associação para facilitar a memorização; e fazer revisões diárias para auxiliar o aluno a conectar informações novas com o conhecimento prévio (MOUSINHO et al, 2015, p?).

Em outro enfoque, o aluno com dislexia apresenta dificuldades em apresentações orais, discussão e participação em sala, problemas de se expressar através de textos ou desenhos, e de manter a concentração e atenção em ambientes que não lhes serão familiares ou desorganizados. Pois sua capacidade de associação e processamento das informações podem apresentar diferentes variáveis de acordo com a situações em que é exposto. 
Sabendo disso, cabe ao educador facilitar e adaptar possibilidades de avaliar o desempenho do aluno, propondo estratégias que envolvam alterações na forma de resposta as atividades. Dentre elas ressalta-se o grifar partes importantes, selecionar alternativas ou correlacionar, oportunizar modelos de trabalhos e/ou atividades concluídas para que compreenda o que é esperado dele, permitir o uso de materiais de apoio para ajudar no momento da escrita.

O acompanhamento do professor também é fundamental nesse processo, e para isso, acomodar o educando mais próximo possível, garantirá segurança e auxílio na realização das atividades. E também, proporcionar um ambiente livre de distrações (barulhos, informações desnecessárias ou objetos) também são de grande valia ao longo do processo.

Outro aspecto importante é a questão do tempo que será dispensado para a realização das atividades. Mousinho et al (2015) ressaltam que:

\footnotetext{
A flexibilidade de tempo para a realização das atividades é um fator fundamental para os alunos que trabalham mais lentamente nas atividades escritas. Podem-se oferecer atividades práticas adicionais para os alunos que necessitam de mais treinamento para dominar competências ou conteúdos; e, finalmente, substituir atividades avaliativas por versões orais ou escritas, dependendo da necessidade (MOUSINHO et al, 2015, p?).
}

Sabendo dessas estratégias, o educador tem recursos para proporcionar uma aprendizagem significativa e eficaz ao educando, levando em conta a individualidade de cada aluno. No entanto, é válido mencionar que para que tais estratégias sejam adequadas, o educador deve trabalhar amparado em um diagnóstico realizado por profissionais qualificados. O qual norteará todo o trabalho pedagógico com o aluno com dislexia.

\section{CONSIDERAÇÕES FINAIS}

Com o desenvolvimento do artigo, verificou-se a importância de conhecer e compreender os desafios que pode se encontrar no ambiente escolar. Sabe-se que o professor precisa ampliar suas possibilidades de trabalho, através de atitudes planejadas e embasadas na realidade de cada aluno, as quais sejam também norteadas por um diagnóstico preciso e eficaz, que embasará todo o trabalho pedagógico.

O aluno que é diagnosticado com dislexia irá apresentar ao longo do processo de aquisição da leitura e escrita, dificuldades em reconhecer, decodificar e transcrever símbolos, letras e números, o que irá refletir no processo de leitura e escrita. Por tais 
motivos, todo o ambiente escolar aliado ao trabalho do educador deverá preparar espaços e oportunidades que atendem as necessidades dos educandos, bem como, facilitem o processo de aprendizagem do indivíduo.

Outro aspecto relevante que foi analisado com o desenvolvimento do presente artigo, é a de propor estratégias adequadas de ensino que facilitem a aprendizagem, formas diferenciadas de analisar e avaliar o desempenho de cada aluno.

\section{REFERÊNCIAS}

COLL C. et al., Desenvolvimento psicológico e educação: necessidades educativas especiais e aprendizagem escolar. Porto Alegre: Artes Medicas Sul, 1995. v. 3.

COLL C. et al., Desenvolvimento psicológico e educação. Porto Alegre: Artes Medicas Sul, 2004 .

COMUNIDADE APRENDER CRIANÇA. Cartilha da inclusão escolar: inclusão baseada em evidências científicas. Ed. Instituto Glia, 2014.

Dislexia: disponível em http://drauziovarella.com.br/crianca-2/dislexia/ acesso em i2 de abril de 2018.

DSM - IV. Manual diagnóstico e estatístico de transtornos mentais. 4 ed. Porto Alegre. Artes Médicas, 2009.

FRANK, R. A vida secreta da criança com dislexia. São Paulo: M. Books, 2003.

HONORA M. \& FRIZANCO M. L., Esclarecendo as deficiências: Aspectos teóricos e práticos para contribuir com uma sociedade inclusiva. Ciranda Cultural, 2008.

MORAIS, A. M. P. Distúrbios da aprendizagem: uma abordagem psicopedagógica. São Paulo: Edicon, $12^{\mathrm{a}}$ edição, 2006.

MOUSINHO, R.; ALVES, L. M.; CAPELLINI, S. A. Dislexia: novos temas, novas perspectivas. Volume III. Rio de Janeiro: Wak Editora, 2015.

PAN M., O direito a diferença. Curitiba: IBPEX, 2008.

TAVARES, H. V. Apoio pedagógico às crianças com necessidades educacionais especiais: dislexia e TDAH. Trabalho de Conclusão de Curso de Pós Graduação em Distúrbios da Aprendizagem pela Faculdade de Medicina do ABC. São Paulo, 2008. 